\section{OBESIDADE INFANTIL: O PROBLEMA DE SAÚDE PÚBLICA DO SÉCULO 21}

De acordo com a World Health Organization (WHO) $)^{(1)}$, a obesidade infantil é um dos mais sérios problemas de saúde pública do século 21, sendo considerado global e afetando principalmente países de baixa e média rendas em áreas urbanas. A prevalência da doença tem aumentado de modo alarmante e, em 2010, o número de crianças menores de cinco anos com sobrepeso foi de mais de 42 milhões, sendo 35 milhões residentes em países em desenvolvimento.

No Brasil, o aumento da obesidade é preocupante. O VIGITEL 2013 ${ }^{(2)}$ apresenta dados referentes à entrevista realizada com 45,4 mil brasileiros, residentes nas capitais e Distrito Federal (DF), onde 51\% dessa população estava com excesso de peso e $17 \%$, com obesidade. Em 2006, os números eram $43 \%$ e $11 \%$.

Além disso, de acordo com a Pesquisa de Orçamento Familiar - POF (2008$2009)^{(3)}$, realizada pelo IBGE, uma em cada três crianças brasileiras com idade entre 5 e 9 anos está com peso acima do recomendado pela $\mathrm{WHO}^{(1)}$ e pelo Ministério da Saúde (MS).

Entre os jovens de 10 a 19 anos, um em cada cinco apresenta excesso de peso. O problema já afeta $1 / 5$ da população infantil e pode resultar em uma geração futura de obesos, pois crianças obesas se tornam adolescentes obesos e $80 \%$ destes chegam à vida adulta também com obesidade. Assim, essa geração de pequenos obesos pode ser vista como futuros hipertensos, diabéticos, com riscos renais, cardiovasculares e cerebrais aumentados. Todos esses fatores reforçam a obesidade infantil como um importante problema de saúde pública no momento em que finaliza o ciclo com indivíduos "sem saúde" e elevados custos para o sistema de saúde pública do país.

O Brasil apresenta uma dupla carga de doenças com origem na alimentação, sendo observada a ocorrência de enfermidades causadas pela deficiência de micronutrientes específicos e crescente prevalência de obesidade entre os brasileiros $^{(4)}$. A alimentação inadequada e o sedentarismo têm sido destacados como as principais causas da obesidade infantil. Em uma avaliação sobre os alimentos mais ingeridos pelos brasileiros, foi encontrado que refrigerantes, refrescos, doces e salgados estão entre os 10 alimentos mais consumidos pelos adolescentes, entre os quais não aparecem frutas e vegetais. Esse padrão alimentar reflete os crescentes números de excesso de peso e obesidade nessa faixa etária ${ }^{(5)}$.

Este número da RBPS apresenta resultados ${ }^{(6)}$ acerca dos hábitos alimentares de adolescentes obesos de escolas públicas e privadas da cidade de Fortaleza, mostrando que $56,3 \%$ não realizavam o café da manhã, $70 \%$ não faziam as refeições junto com a família, 56,9\% consumiam refrigerantes mais de 3 vezes por semana e mais de 30\% frequentavam fast-food. Corroborando com esses hábitos alimentares inadequados, quase $30 \%$ dos adolescentes entrevistados foram considerados sedentários ou insuficientemente ativos. Esses achados mostram evidentes fatores de risco para a manutenção da obesidade entre esses adolescentes e refletem os dados do VIGITEL (2013)(2), segundo os quais Fortaleza apresenta 17,5\% da sua população adulta com diagnóstico de obesidade.

A alimentação infantil é também coordenada pelos hábitos alimentares dos gestores da família. Assim sendo, os adultos brasileiros também fazem uso de refrigerantes e refrescos, mas apresentam entre os 10 alimentos mais consumidos a salada verde ${ }^{(5)}$. Considerando a influência da alimentação dos pais sobre as escolhas das crianças, é fácil perceber que os hábitos alimentares dos pequenos brasileiros estão apoiados sobre os pilares das escolhas inadequadas dos pais. Dessa forma,

\section{Editorial}

\section{Sara Maria Moreira Lima}

Verde $^{(1)}$

1) Universidade de Fortaleza - UNIFOR Fortaleza - CE - Brasil 
qualquer intervenção que busque reverter a crescente incidência da obesidade infantil precisa ser trabalhada juntamente com os responsáveis pela aquisição do gênero alimentício: os pais ou responsáveis ${ }^{(7,8)}$.

Além da aquisição, o ambiente de realização da refeição, a mídia televisiva, que abrange a "massa" da população, e o ambiente escolar também precisam ser vistos como determinantes dos hábitos e escolhas alimentares dos pequenos infantes, portanto, locais certos para a ação de educação nutricional e incentivo à atividade física ${ }^{(9)}$.

Tem sido bem documentada a associação entre a obesidade na infância e sua permanência na adolescência e idade adulta, bem como o desenvolvimento de comorbidades ao longo da vida. Atualmente, as doenças cardiovasculares, diabetes e câncer respondem por $63 \%$ de todas as mortes no mundo. Sobrepeso e obesidade em crianças são o provável início da obesidade na idade adulta e também o início do desenvolvimento de doenças não transmissíveis como diabetes e doença cardiovascular. Sobrepeso e obesidade são doenças crônicas altamente preveníveis, mas a duração da obesidade é um fator de risco, independentemente do IMC na idade adulta ${ }^{(7,8)}$. Existe risco aumentado em 2,5 de mortalidade a cada duas décadas de obesidade do indivíduo ${ }^{(7)}$.

Todas as comorbidades envolvidas com a presença da obesidade podem ter consequências que extrapolam o corpo do indivíduo e chegam à saúde coletiva no instante em que o obeso trata suas doenças crônicas no serviço público e, desse modo, "injeta" um custo adicional ao tratamento da doença. Assim, considerando os fatores ambientais, entre os quais, alimentação e atividade física, e também o papel do esclarecimento dos pais e da sociedade quanto às escolhas alimentares saudáveis, bem como todos os aspectos emocionais envolvidos com o ato de alimentar-se de uma criança, determinantes no aumento do peso, reforça-se a importância das políticas públicas que visem a prevenção da obesidade nessa faixa etária, a fim de minimizar as consequências epidemiológicas das doenças crônicas originárias dessa condição.

Entretanto, é incoerente não falar dos prejuízos psicológicos que acompanham a criança e o adolescente obeso. Não se pode desvincular peso corporal e imagem corporal. Aos dois anos de idade, a imagem corporal da criança já está formada. Entretanto, aos 7 anos, a criança começa a ter noção das dimensões do seu corpo e a se importar com as modificações que acontecem nele. Nesse momento, por influência do grupo ao qual pertence ou deseja pertencer, sua relação com o alimento muda, sendo $\mathrm{o}$ ato de alimentar-se visto como uma forma de inserçãa ${ }^{(9)}$.

Assim, sensibilizada com esses questionamentos sobre a obesidade infantil, a RBPS apresenta, rotineiramente, artigos contendo investigações coerentes, a fim de que a prática alimentar seja firmada como garantia da manutenção da saúde e prevenção de doenças nessa fase de formação da personalidade, e incentiva a busca por intervenções sobre as escolhas alimentares saudáveis, que, obrigatoriamente, precisam ser reforçadas e apreendidas por todos que pensam em um futuro com menos obesos e mais crianças saudáveis.

\section{REFERÊNCIAS}

1. World Health Organization - WHO. Global strategy on diet, physical activity and health: childhood overweight and obesity [relatório na internet; acesso em 2014 Ago 20]. Geneva: WHO; 2014. Disponível em: http://www. who.int/dietphysicalactivity/childhood/en/.

2. Ministério da Saúde (BR). VIGITEL 2013: Vigilância de fatores de risco e proteção para doenças crônicas por inquérito telefônico [relatório na internet; acesso em 2014 Ago 20]. Brasília: Ministério da Saúde, 2014. Disponível em: ttp://portalsaude.saude.gov.br/images/ pdf/2014/abril/30/Lancamento-Vigitel-28-04-ok.pdf.

3. Instituto Brasileiro de Geografia e Estatística - IBGE. Pesquisa de orçamento familiar 2008-2009: análise do consumo alimentar pessoal no Brasil. Rio de Janeiro: IBGE; 2011.

4. Araujo MC, Bezerra IN, Barbosa FS, Junger WL, Yokoo EM, Pereira RA, et al. Consumo de macronutrientes e ingestão inadequada de micronutrientes em adultos. Rev Saúde Pública. 2013;47(Supl 1):1775S-89S.

5. Souza AM, Pereira RA, Yokoo EM, Levy RB, Sichieri R. Alimentos mais consumidos no Brasil: Inquérito Nacional de Alimentação 2008-2009. Rev Saúde Pública. 2013;47(Supl 1):190S-9S.

6. Campos LF, Almeida JZ de, Campos FF, Campos L de A. Prática alimentar e de atividade física em adolescentes obesos de escolas públicas e privadas. Rev Bras Promoç Bras. 2014(1):92-100.

7. Abdullah A, Stoelwinder J, Shortreed S, Wolfe $\mathrm{R}$, Stevenson C, Walls H, et al. The duration of obesity and the risk of type 2 diabetes. Public Health Nutr. 2011;14(1):119-26.

8. Inge TH, Ling WC, Jenkins TM, Courcoulas AP, Mitsnefes M, Flum DR, et al. The effect of obesity in adolescence on adult health status. Pediatrics. 2013;132(6):1098-104.

9. Laus MF, Nascimento PCBD, Almeida SS, Costa TMB. Determinantes do comportamento alimentar. In: Diez-Garcia RW, Cervato-Mancuso AM, Vannucchi H. Nutrição e Metabolismo: mudanças alimentares e educação nutricional. Rio de Janeiro: Editora Guanabara Koogan; 2010. p. 118-27. 